\title{
Yapay Sinir Ağları Analizi İle İmalat Süreçlerinin İyileştirilmesi
}

\author{
Improvement of Manufacturing Processes by Artificial Neural Networks \\ Analysis
}

Salih AKA ${ }^{1}$, 0000-0002-6386-8582 Gökhan AKYÜZ2

\begin{abstract}
ÖZET
Imalat süreçleri çok sayıda değişken tarafından etkilenen faaliyetlerden oluşmaktadır. Bu çalışmanın amacı imalat süreçlerinin planlanması, gelecek durumunun tahmin edilmesi, takip ve kontrolü gibi aşamalarda yapay sinir ağları yöntemi kullanılarak iyileştirmeler yapılabileceğini göstermektir. Çalışmada, 15 girdi değişkenine sahip bir imalat süreci, yapay sinir ağları yöntemi ile modellenmiş, ağın eğitilmesi sağlanmış ve mevcut durumda en iyi çıktı performansı alabilmek için eğitilen ağ kullanılmıştır. Yapay sinir ağları, değişkenlerde meydana gelebilecek herhangi bir değişim karşısında ortaya çıkabilecek sonuçların tespitinin sağlanmasında ve bu yolla süreçlerin iyileştirilmesinde faydalı bir araçtır. Sonuçlar, yapay sinir ağı modellerinin imalat süreçlerine iyi adapte olabildiğini göstermektedir.
\end{abstract}

Anahtar Kelimeler: Yapay sinir ağları, üretim ve imalat süreçleri, süreç iyileştirme

\section{GíRiş}

Üretim yönetiminin bir alt dalı olan imalat, farklı değişkenlerin doğrudan ya da dolaylı olarak etkilediği üretim süreçlerinden oluşmaktadır. İmalat sistemlerinin kalitesi, bu üretim süreçleri karakteristiklerinin tanımlanıp, süreci etkileyen parametre ve değişkenlerin ortaya konulmasına bağlıdır. Sonrasında ise süreçlerin doğru kurgulanarak sistemin bütünsel bir şekilde çalışmasının izlenmesi gerekmektedir. İmalat süreçlerini etkileyen değişkenlerdeki herhangi bir değişim hem sistemin çalışmasını aksatıp maliyet kayıplarına hem de süreç ve ürün kalitesinin azalmasına sebebiyet vermektedir.

\begin{abstract}
Manufacturing processes consist of activities affected by a large number of variables. The aim of this study is to show that improvements can be made by using artificial neural network methods at stages of manufacturing such as planning of processes, forecasting of the future situation, monitoring and control. In the study, a manufacturing process with 15 input variables was modeled using artificial neural networks, network training was provided, and a trained network was used to obtain the best output performance in the current situation. Artificial neural networks are useful tools in finding out the consequences of any change that may occur in variables and in improving the processes with this way. The results show that artificial neural network models can be well adapted to manufacturing processes.
\end{abstract}

Keywords: Artificial neural networks, production and manufacturing processes, process improvement

İmalat sistemlerinin temel amacı nihai müşteri talebine yeterli arzı sağlayabilmektir. Buradan hareketle sistemin tetikleyicisinin müşteri talebi olduğu söylenebilir. Süreçlerin faaliyetleri de bu talebe göre ayarlanmaktadır. İmalat sistemi içerisindeki her bir ardıl süreç arasında tedarikçi müşteri ilişkisi bulunmaktadır. Ardıl süreçlerde sistemi etkileyen değişkenleri gözlemlemek ve gerekli optimizasyonu sağlamak nispeten daha kolaydır. Fakat ardıl olmayan çok değişkenli süreçlerde kalite unsurlarının gözlemlenmesi ve gerekli müdahalenin yapılabilmesi için farklı yaklaşım ve tekniklere ihtiyaç duyulabilmektedir (Yu vd., 2009). 
Günümüzde imalat süreçlerinin daha etkin ve esnek olmasını sağlamak için çeşitli bilgisayar destekli karar destek sistemlerinden faydalanılmaktadır (Ding ve Matthews, 2009). Bu sistemler yardımıyla süreçlerin değişen müşteri talebine, hammadde tedarikindeki aksamalara, üretim içi aksaklıklara karşı daha duyarlı hale gelmesi sağlanabilmektedir. Yapay sinir ağları imalat süreçlerinde faydalanılabilecek bu tarz yöntemlerden biridir.

Yapay sinir ağları 7 farklı özellikteki problemlemler için çözüm sunabilmektedir (Basheer ve Hajmeer, 2000): örüntü sınıflama, kümeleme (Thomassey ve Happiette, 2007), fonksiyon modelleme, tahmin (Zhang vd., 1998), optimizasyon (Azadeh vd., 2010), birleştirme ve kontrol (Levin ve Narendra, 1993). Yapay sinir ağlarının bu özellikleri vasıtasıyla sahip olduğu çözüm kabiliyetleri imalat problemleri için de faydalıdır. İmalat ve genel olarak üretim yönetimi alanındaki mühendislik tasarımı, kalite kontrol, depo tasarımı, stok kontrol, tedarik zinciri yönetimi, talep tahmini, izleme ve teşhis, süreç seçimi gibi problemlerde yapay sinir ağlarının kullanıldığı çeşitli çalışmalar bulunmaktadır. (Hakimpoor vd., 2011).

Bu çalışmada ayna üretimi yapan bir işletmenin imalat süreçlerini etkileyen değişkenler incelenmiş ve yapay sinir ağı yöntemi aracılığıyla bu değişkenler arasındaki en uygun konfigürasyon elde edilerek imalat süreçlerinin optimizasyonu amaçlanmıştır. Çalışmanın ikinci kısmında imalat ve üretim alanında yapay sinir ağlarını kullanan uygulamalardan bahsedilmiş, üçüncü kısımda yapay sinir ağları, yapısı ve çalışma mekanizması tanıtılmıştır. Dördüncü kısımda imalat süreçleri ve süreci etkileyen değişkenler tanıtılmış, gerçekleştirilen uygulama ve sonuçlar sunulmuştur. Sonuç kısmında çalışmanın sağladığı katkı ve çalışmanın geliştirilebilir yönleri belirtilmiştir.

\section{LITERATÜR}

Yapay sinir ağları, insan fizyolojisindeki sinir iletim sisteminden esinlenilerek geliştirilmiş, karmaşık gerçek hayat problemlerini içeren ve bir çok disiplin tarafından kullanılabilirliği kabul edilmiş bir yapay zeka tekniğidir (Ding ve Matthews, 2009). Yapay sinir ağları nöron ya da node adı verilen temel işlemci unsurlarıyla verinin işlenmesini ve bilginin elde edilmesini sağlamaktadır. Yöntem problemler karşısında insana özgü iletim sistemini taklit ederek girdi değişkenlerinden çıktı sonuçları üretmektedir (Abbasi, 2009). Doğrusal olmayan veriyi işlemesi, var olan sistem ile yüksek paralellik göstermesi, gürbüz sonuçlar elde etmesi, hata toleransının olması, öğrenme yeteneği ve kesinlik elde edebilmek için bulanık ve benzeri yöntemlerin entegre edilebilmesi gibi sebeplerden dolayı yöntem bir çok disiplin tarafından çekici bulunmaktadır (Basheer ve Hajmeer, 2000).

Yöntem, sınıflama (Lacher vd., 1995), tahmin (Haas vd., 1995; Efendigil vd.,2009), optimizayon (Hurrion, 1997; Azimi ve Soofi, 2017), izleme (Upadhaya ve Eryureka, 1992; Alguindigue vd., 1993) ve kontrol (Andersen vd., 1990; Abbasi, 2009) gibi kabiliyetleri sayesinde üretim ve imalat sistemlerinde kullanılabilmektedir. Yoo vd. (2009) kapalı döngü tedarik zincirinde hedeflenen müşteri servis düzeyini yakalayabilmek için talep tahminine ihtiyaç duymayan, RFID veriyi öğrenebilme yeteneği ile dönüştürüp müşteri talebini öngörebilen ve üretim hızını bu talebe göre düzenleyen bir yapay sinir ağı modeli önermişlerdir.

Tahmin yönü, yapay sinir ağlarının kullanıldığı problemler içerisinde, yöntemin öne çıkan fonksiyonlarından biri olarak görülmektedir. Burduk vd. (2017) belirlediği değişkenlerin üretim programları üzerindeki etkilerini görmek ve bu yolla üretim seviyesinin tahmini için yapay sinir ağlarını kullanmıştır. İnceledikleri tesiste kaynaklara ulaşım kısıtlı olduğundan değişen müşteri siparişlerinin zamanında yetiştirilmesine, bu amaçla üretim seviyesinin iyi ayarlanmasına ihtiyaç duyulmaktadır. Confalonieri vd. (2015) enerji yoğun bir imalat tesisinin süreç optimizasyonu ve önleyici bakım faaliyetleri için yapay sinir ağları temelli bir karar destek sistemi geliştirmişlerdir. Yapay sinir ağlarının önleyici bakım için sisteme sağladığı girdiler, muhtemel anormalliklerin ve bunlarla ilgili kurtarma faaliyetlerinin belirlenmesinde kullanılmıştır. Benzer olarak Janikova ve Bezak (2016) girdi değişkenlerinde yapılacak dengelemeyle daha iyi bir üretim hattı performansı sergilemeyi amaçlamışlardır. Yapay sinir ağlarının ürettiği değerler ile ölçülen değerler arasında elde ettikleri yüksek korelasyon yöntemin amaca hizmet ettiğini göstermektedir. Lechevalier vd. (2015) geliştirdikleri algoritma, yapay sinir ağlarının üretim problemlerine daha kolay adapte edilebilmesi ve bu sistemler için gerekli verinin yetersiz olduğu durumda sistemin ihtiyaç duyduğu verinin sağlanabilmesi için alternatif bir yol önermektedir. Wang vd. (2016) yapay sinir ağlarının tahmin yeteneğinden faydalanarak, sistem dengesini sağlayacak, sistemdeki beklemeleri ve kayıpları telafi edebilecek bir yaklaşım sunmuşlardır. Çalışmanın sonuçları, yapay sinir ağlarının süreç kontrolünün efektif bir şekilde gerçekleştirilmesinde kullanılabilecek araçlardan biri olabileceğini işaret 
etmektedir. Chou vd. (2016) ileri beslemeli yapay sinir ağı modelini Taguchi parçacık sürü optimizasyonu yöntemiyle birleştirmişlerdir. Söz konusu yöntem literatürdeki benzerlerine kıyasla daha iyi girdi-çıktı analizi performansı göstermektedir. Yapay sinir ağı temelli bu yöntem hesaplamalar açısından daha verimli ve daha gürbüz sonuçlar üretebilmektedir. Wang (2007) imalat süreçleri için üretim maliyetini hesaplayabilen, mevcut üretim verisinden ileride oluşacak maliyeti tahmin eden, süreç maliyetine odaklanmış bir model geliştirmiştir. Enerji ihtiyacının tahmininde (González-Romera vd., 2008) veya tedarik zincirinde kamçı etkisinin azaltılmasında (Carbonneau vd., 2008) yapılan çalışmalarda da yapay sinir ağlarının tahmin yönünün etkinliğine vurgu yapılmaktadır.

Yapay sinir ağları, üretim ve imalat sistemlerinin farklı süreçlerinin geliştirilmesine de katkı sağlamaktadır. Gumus vd., (2010) birden fazla aşamalı bir envanter sisteminde bekleme sürelerini optimize ederek toplam süreç performansının iyileşmesine yardımcı olan bir model önermişlerdir. Lin vd. (2009) süreçlerin düşük verimlilik göstermesinde süreç içi stokların büyük rolü olduğunu belirtmişlerdir. Buradan hareketle Ardışık Kuadratik Programlama (SQP) ile entegre ettikleri yapay sinir ağı modeli yoluyla optimal stok seviyesini belirlemeye çalışmışlardır.

Sürecin mevcut durumunu izleme ve elde ettiği verilerden çıkardığı sonuçlarla süreçlerin çalışma mekanizmasına katkıda bulunarak süreçlerin kalitesinin iyileştirilmesi, yapay sinir ağlarının üretim ve imalat alanındaki yeteneklerinden biridir. Fast ve Palme (2010) fabrikanın mevcut durumunu sürekli olarak izleyen ve elde ettiği operasyonel veriler üzerinden çalışarak fabrikanın bakım ve performans optimizasyonunu sağlayan yapay sinir ağı temelli bir model kullanmışlardır. Benzer olarak, Mitoma vd. (2008) tesis içi makine rotasyonunu sürekli olarak takip ederek durum gözetimi ve arıza teşhisinde bulunarak hatalara erken müdahale edilmesine olanak sağlayan Parçalı Doğrusal Yapay Sinir Ağı modeli geliştirmişlerdir.
Yöntem süreçlerin izlenmesi, hataların tespit edilmesi ve bu yolla kalite standartlarının geliştirilmesi açısından oldukça kullanışlıdır (Chen ve Liu, 2000; Sciuto vd., 2009).

\section{YAPAY SINIR AĞLARI}

Yapay sinir ağları, birçok geleneksel yöntemden üstün olarak tecrübe ya da gözlemlerle hakkında çıkarım yapılabilecek tanımlaması ve hakkında bilgi edinilmesi zor her türlü veriye iyi uyum sağlayabilmektedir (Zhang vd., 1998). Ancak, yöntem bu özelliğini kullanabilmek için çok sayıda veri ve gözleme intiyaç duymaktadır. Kesinlik veya belirsizlik içerebilen gerçek hayat problemlerinde, yapay sinir ağları bu özelliğini kullanarak tatminkâr sonuçlar üretebilmektedir.

Yöntemin bir diğer yararı eksik veri olmasına rağmen öğrenebilme özelliği sayesinde problemin gelecek perspektifi hakkında bilgi sağlayabilmesidir. Girdi ve çıktı ilişkisine dayalı mevcut veriler, yapay sinir ağının kendini eğitmesi için yardımcı olmaktadır. Ayrıca bu öğrenme özelliği yapay sinir ağına probleme özgü esneklik sağlamaktadır (Zhang vd., 1998). Yapısal olarak kısıtlı birçok istatistik tekniğinin aksine, bu yöntem geniş bir çalışma alanında kullanılabilmektedir.

Yapay sinir ağlarının çalışma mekanizmasının temelinde nöron adı verilen unsurlar, katmanlar arasında çok yönlü bağlantı kurulmasını sağlamakta ve bu bağlantının gücüne göre ağılıklandırılmaktadır. Kendi aktivasyon fonksiyonuna sahip her bir nöron önce eğitime sonra da teste tabi tutularak en uygun ağırlık değerini alması sağlanmaktadır (Abbasi, 2009). Yapay sinir ağları, Rosenblatt (1958) tarafından geliştirilmiş perceptronlar yoluyla deneyerek öğrenmekte ve bu aşamada ağırlıkların güncellenmesi sağlanmaktadır. Yöntem dâhilinde değişken, sabit, modifiye edilmiş ve ayarlanmış şeklinde isimlendirilmiş 4 farklı karakterde ağırlık değişkeni bulunmaktadır (Wang, 2007). Şekil 1'de çok katmanlı ileri beslemeli yapay sinir ağı modeli görülmektedir.

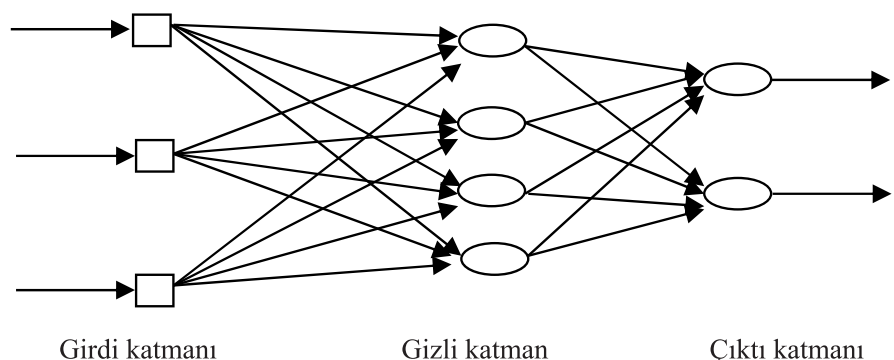

Şekil 1: Çok katmanlı ileri beslemeli yapay sinir ağı modeli (Hakimpoor vd., 2011) 
İleri beslemeli ağ için kullanılan birçok algoritmanın yanında, geri yayılım algoritması basitliği ve önemi itibariyle oldukça yaygın tercih edilmektedir. Geri yayılım algoritması aşağıdaki şekilde tanımlanmaktadır (Basheer ve Hajmeer, 2000). Öncelikle $L$ çok katmanlı $l \in\{1,2, \ldots L\}$ bir yapay sinir ağında ardışık iki katmanın göz önüne alınması gerekmektedir. Bu yapıda $N_{l}$ düğüm ve her iki düğüm arasında katmanları bağlayan bağlantılar tanımlanmaktadır. Bu bağlantıların ağırlıkları $W \in R^{N_{l} \times N_{l-1}}$ ile gösterilmektedir. Her bir düğüm kendi aktivasyon işlemiyle $x_{j}$ sinyalini üretmektedir. Bu aşamada $l-1$. katmandaki $x_{i}^{l-1}$ ve $l$.katmandaki $x_{j}^{l}$ arasında oluşacak bağlantının ağırığı $w_{j i}^{l}$ ile ifade edilmektedir. $w_{j i}^{l}$ ile gösterilen bağlantı ağırlığı $l$. ara katmanda yer alarak, aynı katmanda bulunan $j$. düğümün $j \in\{1,2, \ldots J\}$ bir önceki $l-1$. katmandaki $i$. düğüme $i \in\{1,2, \ldots I\}$ bağlanmasını sağlamaktadır, Ağırlık ve aktivasyon sinyalizasyonunun çarpımı $\xi_{j i}^{l}$ net etkiyi üretmektedir (Denk.1).

$$
\xi_{j}^{l}=\sum_{i=1}^{N_{l-1}} w_{j i}^{l} x_{i}^{l-1}
$$

Aktivasyon ise $\sigma$ transfer fonksiyonu kullanılarak elde edilmektedir.

$$
x_{j}^{l}=\sigma\left(\xi_{j}^{l}\right)=\sigma\left(\sum_{i=1}^{N_{l-1}} w_{j i}^{l} x_{i}^{l-1}\right)
$$

Sigmoid fonksiyonu, yapay sinir ağları aktivasyon işlemlerinde tercih edilebilir fonksiyonlardan biridir.

$$
\sigma(\xi)=\frac{1}{1-e^{-\xi}}
$$

Bu aşamadan sonra aynı katmanda, düğümler arasındaki ağılık değerleri bir önceki durumundan yeni durumuna güncellenmektedir.

$$
w_{j i}^{l}(t)=w_{j i}^{l}(t-1)+\Delta w_{j i}^{l}(t)
$$

Delta kuralı ile belirlenen $\Delta w_{j i}^{l}$ kuralı pozitif ya da negatif yönlü olabilmektedir.

$$
\Delta w_{j i}^{l}=\varphi \delta_{j}^{l} x_{i}^{l-1}+\mu \Delta w_{j i}^{l}
$$

Burada önceki $\Delta w_{j i}^{l}$ değişim değeri $\mu$ momentum katsayısı ile çarpılmakta ve $l-1$. katmanın sinyalizasyon değeri $x_{i}^{l-1}, \varphi$ öğrenme oranı ile güncellenmektedir. Alternatif bir yol olarak $\Delta w_{j i}^{l}$ değeri dereceli alçalma (gradient descent) yöntemi ile de belirlenebilmektedir.

$$
\Delta w_{j i}^{l}=-K\left(\frac{\partial \varepsilon^{l}}{\partial w_{j i}^{l}}\right)
$$

Ağırlık değerlerinin belirlenmesinde faydalanılan Denk.5'de $\delta_{j}^{l}$ değişkeninin de hesaplanması gerekmektedir. Fakat bu değişkenin hesabı bulunduğu katmana göre değişebilmektedir. Çıktı katmanı $l=L$ için değişken hesabı Denk.7'de görülmektedir.

$$
\delta_{j}^{l}=\left(x_{j}^{L}-y_{j}\right) x_{j}^{L}\left(1-x_{j}^{L}\right)
$$

Söz konusu değişken hesabı, gizli katmanda ise Denk. 8'deki gibi yapılmaktadır.

$$
\delta_{j}^{l}=x_{j}^{L}\left(1-x_{j}^{L}\right)\left(\sum_{k=1}^{r} \delta_{k}^{l+1} w_{k j}^{l+1}\right)
$$

Yapay sinir ağları modelinde geri yayılım algoritmasının kullanılmasıyla mevcut hata çıktı katmanından gizli katmana doğru yayılarak ağırıkların güncellenmesi sağlanmaktadır.

\section{UYGULAMA}

Çalışma ayna üretimi yapan bir işletmenin imalat sürecinde gerçekleştirilmiştir. Süreci etkileyen değişkenler tespit edildikten sonra değişkenler gözlemlenerek günlük ortalama değerleri elde edilmiştir. Çalışmanın amacı imalat sürecini etkileyen değişkenlerin optimum değerlerini yapay sinir ağı modeli aracılığıyla tespit edip süreç performansını iyileştirmektir.

Temel hammaddeleri cam, kimyasallar ve boyalardan oluşan cam imalatı, yıkama, kimyasalların kaplanması ve koruma boyalarının sürülmesi süreçlerinden oluşmaktadır. İlk olarak yıkama ile ham camın kir ve tozdan temizlenmesi sağlanır. Suyun temiz olamaması, kir ve toz, kimyasalların cam üzerine yapışmasını ve yayılımını engelleyerek ayna kalitesini düşürmektedir. Bu nedenle, kimyasal kaplama aşamasından önceki son yıkamada ve sonraki aşamalarda ısıtılmış saf su kullanılmaktadır. Kimyasal kaplama aşamasında, cam üzerine kimyasallar kaplanmaktadır. Bu aşamada, kimyasalların kullanım miktarı, cam üzerindeki yayılımı, hava kabarcıklarının oluşmaması ve herhangi bir yabancı maddenin cam üzerine yapışmamasına dikkat edilmesi gerekmektedir.

Son safhada, koruma amaçlı olarak kimyasalların üzerine sırasıyla astar ve son kat boyalar sürülmektedir. Bu süreçte, cam üzerindeki yayılımı, son kat boyanın astar boyayı tamamen örtmesi ve boyaların kurutulması sağlanmaktadır. Fırınlama işlemleri sonrası hataların telafi edilmesi mümkün olmamaktadır. Birinci fırında astar boyadan, ikinci ve üçüncü fırınlarda ise fırın çıkışlarından sonra camın sıcaklığıyla ilgili ölçümler yapılmaktadır. 
İmalat hattının yavaşlatılması yoluyla ortam sıcaklığından faydalanarak firınlar arasında camın yüzey sıcaklığının 40-50 dereceye düşürülmesi sağlanmaktadır. Boyalar, bakır ve aktivatör bir gün önceden hazırlanıp dinlenmeye bırakılmaktadır. Diğer kimyasalların hazırlanıp, pompalara takılması ve debi kontrollerinden sonra imalata başlanmaktadır. İmalat hattı üzerine yerleştirilen cam yüzeyi sırasıyla seryum oksit (CeO2), şebeke suyu ve 30-33 dereceye kadar ısıtılmış saf su ile yıkanmaktadır.

Cam temizlendikten sonra kalay, gümüş ve bakır ile kaplanmaktadır. Her bir safhada ara yıkamalar gerçekleştirilmektedir. Birinci fırın aracılığıyla kurutulan cam üzerine astar ve son kat boyalar uygulanmaktadır. Astar boya ikinci fırında, son kat boya ise üçüncü fırında kurutulmaktadır. Üçüncü fırından sonra ISISı 70 derecenin altına düşürülen camın ayna yüzeyi (kimyasalların ve boyaların tatbik edilmediği alt yüzey), sulandırılmış hidroklorik asit (HCl-tuz ruhu, karışımın yaklaşık olarak \%5'lik kısmını oluşturuyor) ile yıkanarak temizlenmektedir. Ayna imalat sürecine çıktı ve süreç değişken özellikleri Tablo 1'de görülmektedir.

Çalışmada süreci etkileyen değişkenlerden hareketle nihai üründeki karşılaşılabilecek hata oranı ve sağlam ürün oranının tahmin edilmesi ve bu yolla hata ve israfın azaltılarak süreç performansının iyileştirilmesi esas alınmıştır. Eldeki mevcut günlük ortalama verisi 15 girdi değişkeni ve 3 çıktı değişkeninden oluşmaktadır. Toplamda 170 günlük veri olması nedeniyle veri matrisi $170 * 18$ boyutundadır.

Tablo 1: Süreç çıktıları ve süreç değişken özellikleri

\begin{tabular}{|c|c|c|c|}
\hline Süreç Çıktısı & Birim & & Ölçüm Yöntemi \\
\hline Sağlam Oranı (SO) & Oran & \multicolumn{2}{|c|}{ Sağlam ürün sayısı / Toplam ürün sayısı } \\
\hline Kimyasal Hata Oranı (KO) & Oran & \multicolumn{2}{|c|}{ Kimyasal hatalı ürün sayısı / Toplam hatalı ürün sayısı } \\
\hline Boya Hata Oranı (BHO) & Oran & \multicolumn{2}{|c|}{ Boya hatalı ürün sayısı / Toplam hatalı ürün sayısı } \\
\hline Süreç Değişkenleri & Birim & Hedef Değer & Ölçüm Yöntemi \\
\hline Hava Sıcaklığı (HSC) & ${ }^{\circ} \mathrm{C}$ & & Dijital termometre \\
\hline Nem (NEM) & $\%$ & & Hygrometre \\
\hline Safsu Sıcaklığı (SSU) & ${ }^{\circ} \mathrm{C}$ & $\mathrm{Y} / \mathrm{K}^{\mathrm{c}}=30$ & $\begin{array}{l}\text { Su Isıtma makinasında bulunan termometrenin } \\
\text { kontrolü ile }\end{array}$ \\
\hline MA280 (MA) & $\mathrm{L} / \mathrm{h}$ & $\begin{array}{l}Y=4-4,5 \\
K=5-6\end{array}$ & $\begin{array}{l}\text { London Lab. motorlarının pompalama } \\
\text { göstergelerin kontrolü ile }\end{array}$ \\
\hline Kalay (KLY) & $\mathrm{L} / \mathrm{h}$ & $\mathrm{Y} / \mathrm{K}=9-10$ & " \\
\hline Gümüş Debi Miktarı (GDB) & $\mathrm{L} / \mathrm{h}$ & $\begin{array}{l}Y=7,5-8 \\
K=10-12\end{array}$ & “ \\
\hline Aktivatör (AKT) & $\mathrm{L} / \mathrm{h}$ & $\mathrm{Y} / \mathrm{K}=2$ & " \\
\hline Amonyak (AMO) & $\mathrm{L} / \mathrm{h}$ & $\mathrm{Y} / \mathrm{K}=2,5-5$ & " \\
\hline Bakır Debi Miktarı (BDB) & $\mathrm{L} / \mathrm{h}$ & $\mathrm{Y} / \mathrm{K}=5-7$ & " \\
\hline Hat Hızı $(\mathrm{HHZ})$ & $\mathrm{cm} / \mathrm{min}$. & $\begin{array}{l}Y=247,9-251,2 \\
K=235,5-241,1\end{array}$ & Kronometre \\
\hline $\begin{array}{l}\text { Birinci Fırından Çıkan Camın } \\
\text { Yüzey Sıcaklığı (FRN1) }\end{array}$ & ${ }^{\circ} \mathrm{C}$ & $\mathrm{Y} / \mathrm{K}=35-40$ & $\begin{array}{l}\text { Orta dalga infraret termometrenin cam yüzeyine } \\
\text { tutulması ile }\end{array}$ \\
\hline $\begin{array}{l}\text { İkinci Fırından Çıkan Camın Yüzey } \\
\text { Sıcaklığı (FRN2) }\end{array}$ & ${ }^{\circ} \mathrm{C}$ & $\mathrm{Y} / \mathrm{K}=75-80$ & “ \\
\hline $\begin{array}{l}\text { Üçüncü Fırından Çıkan Camın } \\
\text { Yüzey Sıcaklığı (FRN3) }\end{array}$ & ${ }^{\circ} \mathrm{C}$ & $Y / K=125-130$ & “ \\
\hline Astar Boya Viskozitesi (ABY) & s. & $\begin{array}{l}Y=25-30 \\
K=30-35\end{array}$ & 4 mm'lik Fordcup'ın boşalma süresi \\
\hline Sonkat Boya Viskozitesi (SBY) & s. & $\begin{array}{l}Y=30 \\
K=40-45\end{array}$ & $"$ \\
\hline \multicolumn{4}{|c|}{ 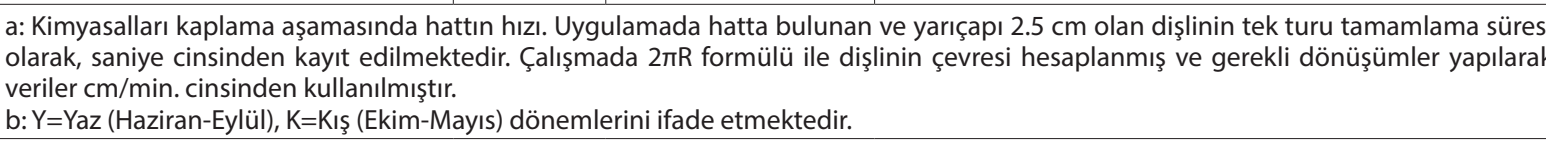 } \\
\hline
\end{tabular}


Verinin analizi için MATLAB programı kullanımıştır. Mevcut verinin \%70'i eğitim, \%20'si geçerlilik ve $\% 10^{\prime} u$ test aşamaları için bölünmüştür. Başlangıç modelinde gizli katman sayısının belirlenmesi karar vericiye bırakılmaktadır. Analiz sonucunda yapay sinir ağı modelinin kötü performans göstermesi ve aşırı uygunsuz sonuçların çıkması durumunda karar verici gizli katman sayısını göreceli olarak artırıp azaltabilmektedir. Buradan hareketle çalışmada, karar vericilerle yapılan görüşmeler doğrultusunda 15 ve 30 gizli katmanın kullanılması kararlaştııımıştır. Yapay sinir ağı modelleri elde çeşitli veri grupları olması durumunda sınıflama, uzun dönemli mevcut veri ışığında ileriki dönemler için tahmin yapabilmektedir. Ayrıca, veri grupları içerisinde çıktı değişkeni olmadığı durumda danışmansız öğrenme yaparak kendisini veriye uyarlayabilmekte ve örneklem grubunu kümeleyebilmektedir. Çalışmada yapay sinir ağlarının bir diğer işlevi simülasyon yoluyla tahmin fonksiyonu kullanılmıştır.

Oluşturulan yapay sinir ağının eğitilmesi için Levenberg-Marquardt Back Propagation algoritmasından faydalanılmıştır. Ağ eğitildikten sonra gerçek durum ile ağın ürettiği sonuçlar arasındaki hata farkının incelenmesi gerekmektedir. Çok katmanlı yapay sinir ağlarında girdi, gizli ve çıktı katmanları arasındaki aktarım fonksiyonu fark yaratabilmektedir. Yapay sinir ağlarında üç tip aktarım fonksiyonundan faydalanılmaktadır. Purelin transfer fonksiyonu binom karakteristikli girdi ve çıktı değişkenlerine sahip modeller için kullanılmaktadır. Bu dar kapsamın aksine doğada var olan doğrusal veya doğrusal olmayan karakteristikteki modeller için Hiperbolik tanjant fonksiyonu (TANSIG) ve Log-sigmoid transfer fonfsiyonu (LOGSIG) tercih edilmektedir (Dorofki vd., 2012). Çalışmada, mevcut verinin eğitilmesi için 15 ve 30 nöronlu gizli katmana sahip ağlar, TANSIG ve LOGSIG alternatifleri doğrultusunda 10 'ar kez çalıştırılmıştır. Her bir çalıştırma sonucunda elde edilen performans verisi kaydedilerek ağların, eğitim, geçerlik ve test aşamaları performans ortalamaları belirlenmiştir. Tablo 2'de görüleceği üzere 15 nöronlu gizli katmana sahip ağ, TANSıG fonksiyonu kullanımında en yüksek performans değerlerine ulaşmaktadır.

Eldeki veriler doğrultusunda en yüksek performansı elde eden 15 nöronlu gizli katmana sahip ağın, süreç performansının iyileştirilmesinde kullanılması uygun görülmüştür. Bu ağın eğitimi sırasında gözlemlenen hata katsayılarından bir örnek Tablo 3'de görülmektedir.

Tablo 2: Ağ alternatiflerinin karşılaştırılması

\begin{tabular}{|c|c|c|c|c|}
\hline Ağ alternatifleri & Eğitim & Geçerlik & Test & Hepsi \\
\hline TANSIG_TANSIG_15 & $\mathbf{0 , 9 9 7 3 3 0}$ & $\mathbf{0 , 9 9 7 5 7 5}$ & $\mathbf{0 , 9 9 7 5 3 2}$ & $\mathbf{0 , 9 9 7 3 7 5}$ \\
\hline TANSIG_LOGSiG_15 & 0,995575 & 0,995538 & 0,995597 & 0,995537 \\
\hline LOGSIG_LOGSiG_15 & 0,995924 & 0,995458 & 0,994826 & 0,995664 \\
\hline LOGSiG_TANSIG_15 & 0,996250 & 0,996374 & 0,996000 & 0,996191 \\
\hline TANSIG_TANSIG_30 & 0,996330 & 0,996904 & 0,995309 & 0,996221 \\
\hline TANSIG_LOGSiG_30 & 0,995797 & 0,995882 & 0,996139 & 0,995840 \\
\hline LOGSIG_LOGSiG_30 & 0,995130 & 0,994428 & 0,995856 & 0,995099 \\
\hline LOGSiG_TANSiG_30 & 0,995785 & 0,996496 & 0,995785 & 0,995870 \\
\hline En iyi değer & 0,997330 & 0,997575 & 0,997532 & 0,997375 \\
\hline
\end{tabular}

Tablo 3: Eğitim sırasında ağda oluşan hata katsayıları

\begin{tabular}{|c|c|c|c|}
\hline Hata Değerleri & MSE & R & $\begin{array}{c}\text { Örneklem } \\
\text { Büyüklüğü }\end{array}$ \\
\hline Eğitim & 0,0013 & 0,99728 & 119 \\
\hline Geçerlilik & 0,0015 & 0,99835 & 34 \\
\hline Test & 0,0031 & 0,99716 & 17 \\
\hline $\begin{array}{c}|c| \\
\text { İterasyon Sayısı }\end{array}$ & \multicolumn{3}{|c|}{15} \\
\hline $\begin{array}{c}\text { Gizli Katman } \\
\text { Nöron Sayısı }\end{array}$ & \multicolumn{3}{|c|}{} \\
\hline
\end{tabular}

MSE, gerçek durum ile ağın tahmin ettiği değerler arasındaki farkın karelerinin ortalamasını vermektedir. $[-1,1]$ aralığında değerler alan $\mathrm{R}$, gerçek ile tahmin değerleri arasındaki korelasyonu ifade etmektedir. Elde edilen değerlerin ilişkinin gücünü göstermesi açısından 1'e yakın olması istenmektedir.

Toplamda 8 iterasyon gerçekleştirilmiş, eğitim için 119, geçerlilik için 34 ve test için 17 örneklem 
kullanılmıştır. Analiz sonucunda MSE ve R değerlerinin istenilen seviyelerde olduğu görülmektedir. Senaryo değerlendirilmesinde esasen korelasyonu ifade eden $R$ değerleri göz önüne alınmaktadır. Ağın eğitilmesi için 170 dönemlik girdi ve çıktı verisinden faydalanılmıştır. Bu haliyle ağda 15 adet nöronlu gizli katman ve 3 adet nöronlu çıktı katmanından bir yapı oluşturulmuştur. Şekil 2'de bu yapı görülmektedir.

Ağda eğitim ve geçerlilik için daha iyi R değerleri elde edilmiştir. Fakat test aşamasında $\mathrm{R}$ değeri diğer aşamalara göre daha düşüktür. Bu durum ağın iyi çalıştırıldığını, geçerlilik analiziyle bunun kanıtlandığını, aynı zamanda ağın ezber yapmadığını göster- mektedir. Bu ağla ilgili regresyon grafikleri Şekil 3'de görülmektedir.

Sağlam oranı, kimyasal hata oranı ve boya hata oranı çıktı değişkenleri için gerçek değerler ile ağın tahmin ettiği değerler arasındaki MSE değerleri ayrı ayrı hesaplandığında sırasıyla 0,0029, 0,0005 ve 0,0002 olarak bulunmuştur. Bu değerler tahmin ile gerçek değer arasındaki sapmaların her bir çıktı değişkeni için küçük olduğu şeklinde yorumlanabilir.

Şekil 4'de ağın performans grafiği görülmektedir. Test ve geçerlik için en düşük hata değeri başlangıç iterasyonunda elde edilmiştir.

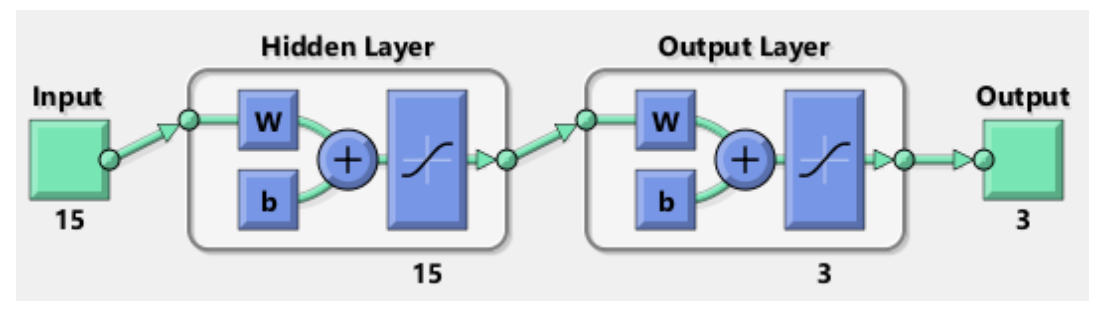

Şekil 2: Yapay sinir ağı modeli yapısı
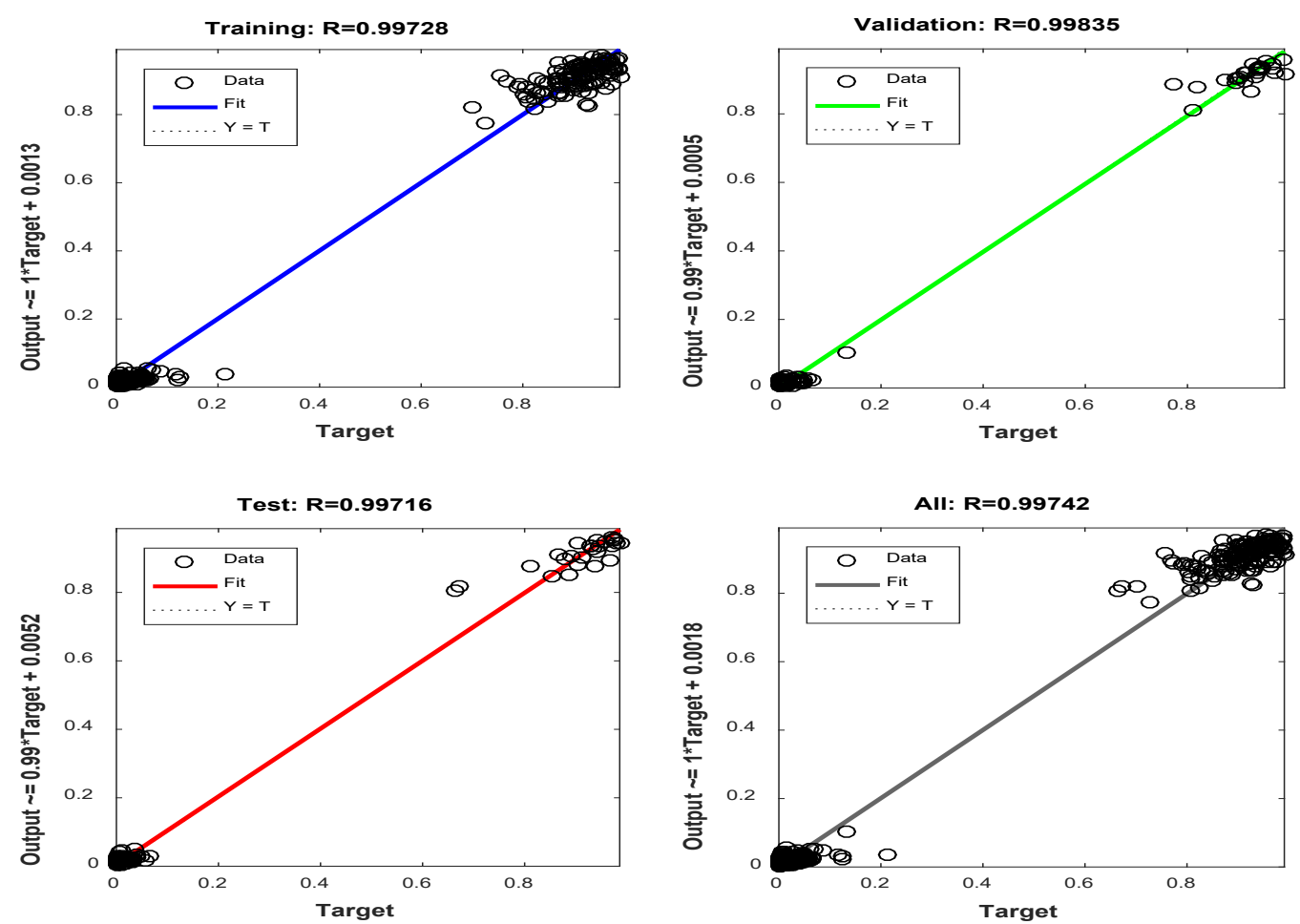

Şekil 3: Eğitim, Geçerlilik ve Test Regresyon Grafikleri 


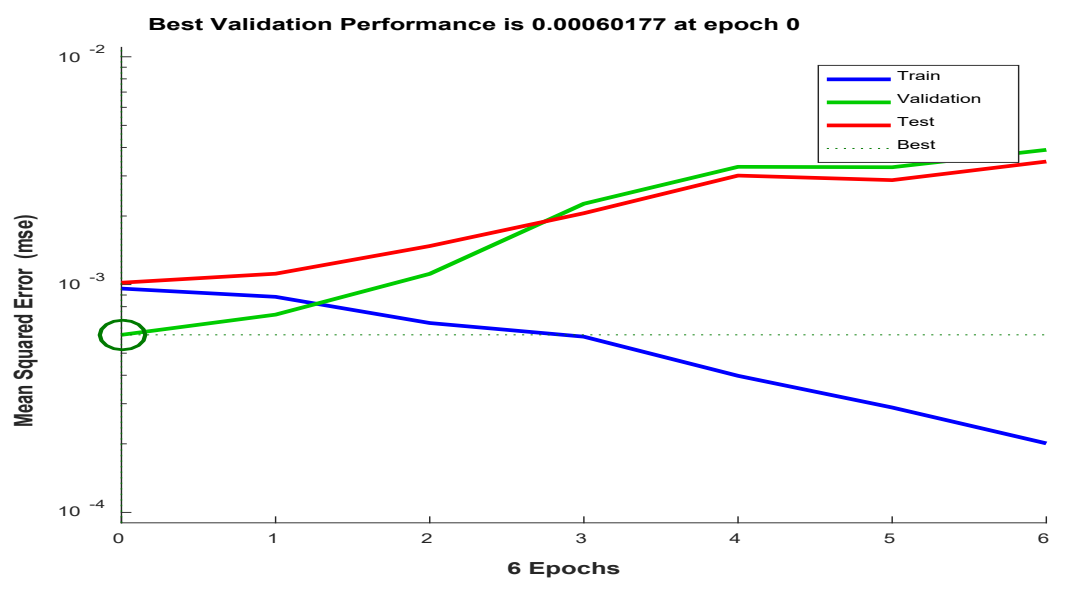

Şekil 4: Ağın Performans Grafiği

Yapay sinir ağının toplamda 170 dönemlik veri ile eğitilmesi ve test edilmesiyle elde edilen sonuçlar gerçek çıktı değerlerine oldukça yakındır. Bu durum kurulan yapay sinir ağı modelinin mevcut 15 girdi değişkeni üzerinden gelecek dönem tahmini yapabileceğini kanıtlamaktadır. Bir başka deyişle girdi değişkenlerinden elde edilecek üretim kompozisyonlarının ne oranda hataya sebep olacağı mevcut model ile tespit edilebilir. Şekil 5'de 170 dönemlik girdi seti kullanılarak model aracılığıyla elde edilmiş sonuçlar ve gerçek hata değerlerinin karşılaştırılması görülmektedir.
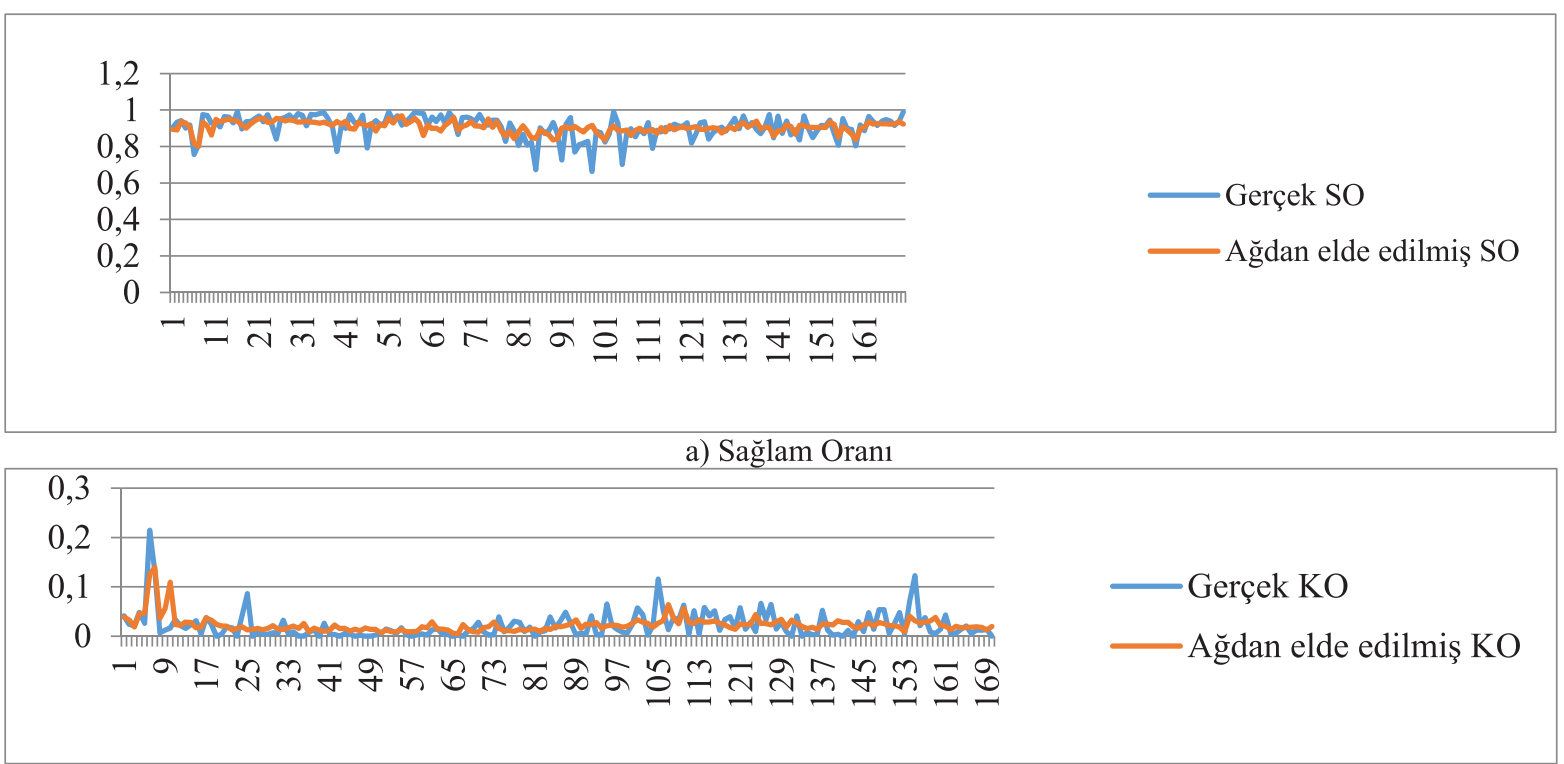

b) Kimyasal Hata Oranı

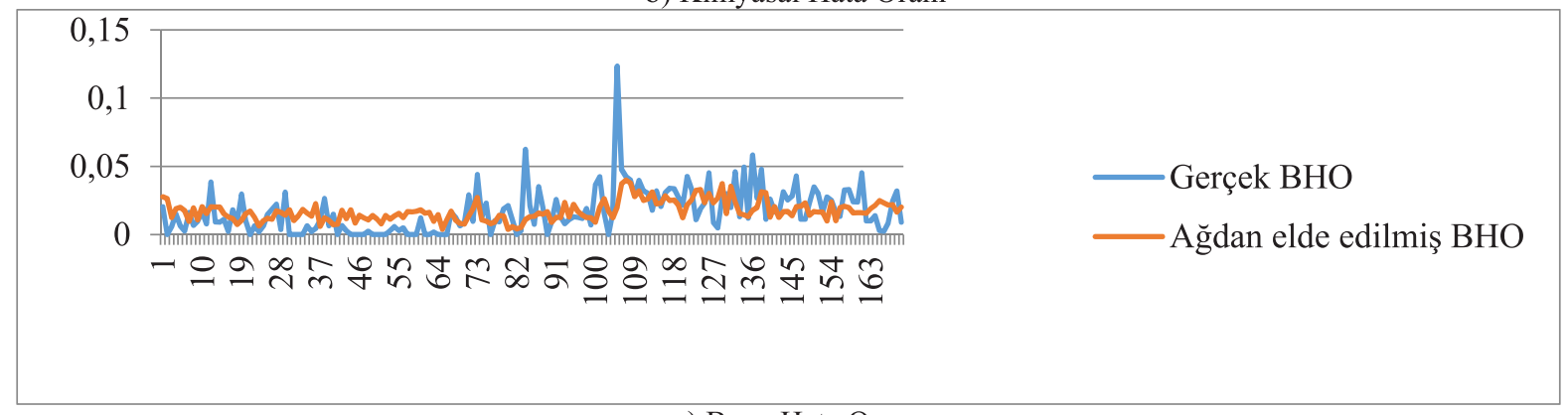

c) Boya Hata Oranı

Şekil 5: Gerçek çıktı ile yapay sinir ağı modeli tarafından üretilen sonuçların karşılaştırılması 
Çalışmanın son aşamasında ileride karşılaşılabilecek 5 farklı üretim senaryosu sonucunda oluşacak hata oranları model aracılığıyla tespit edilmiştir. Yapay sinir ağı modelleri mevcut duruma iyi adapte olabilirken gelecek durum tahminleri için başarılı sonuçlar da üretebilmektedir. İmalat sürecini etkileyen değişkenlerden herhangi biri veya birkaçında görülen bir değişikliğin olası hata sonuçlarını yapay sinir ağı modeli ile tespit etmek mümkündür. Tablo 4'de imalat sürecini etkileyen değişkenlerin oluşturulan senaryolar doğrultusunda aldığı değerler sonucu elde edilen hata oranları yer almaktadır.

Eğitimi tamamlanmış 15 nöronlu gizli katmana sahip yapay sinir ağı yardımıyla muhtemel üretim kompozisyonları karşısında oluşacak hata ve sağlam ürün oranları elde edilmiştir. Bu ve benzeri senaryolar doğrultusunda yapay sinir ağları yardımıyla üretim süreçlerinin iyileştirilmesi mümkün olabilmektedir. Mevcut yapay sinir ağı ideale yakın sonuçlar üretebilmektedir.

\section{SONUÇ}

Yapay sinir ağları öğrenebilme kabiliyeti ve doğada var olan sistemlere adapte olabilme yeteneği nedeniyle çok farklı disiplinlerdeki problemlerin çözümünde kullanılabilmektedir. Üretim ve özellikle imalat problemleri doğası gereği yapay sinir ağlarının entegrasyonuna oldukça açık bir alandır. Herhangi bir imalat sürecinin planlanması, süreç çıktılarının tahmini ve sürecin kontrolü yapay sinir ağları modelleri aracılığıyla kolayca gerçekleştirilebilmektedir. Bu çalışmada ayna üretimi sırasında oluşan hata ve ürünün sağlam oranına etki eden değişkenler yapay sinir ağı modeliyle incelenmiştir. Söz konusu değişkenler doğrultusunda elde edilen veriler kullanılarak yapay sinir ağı eğitilmiş, uygun öğrenme koşulları sağlandıktan sonra farklı üretim kompozisyonlarından oluşan girdi senaryoları model aracılığıyla analiz edilerek süreç sonunda oluşabilecek hata ve sağlam oranları tespit edilmiştir.

Tablo 4: Senaryolar doğrultusunda elde edilen hata oranları

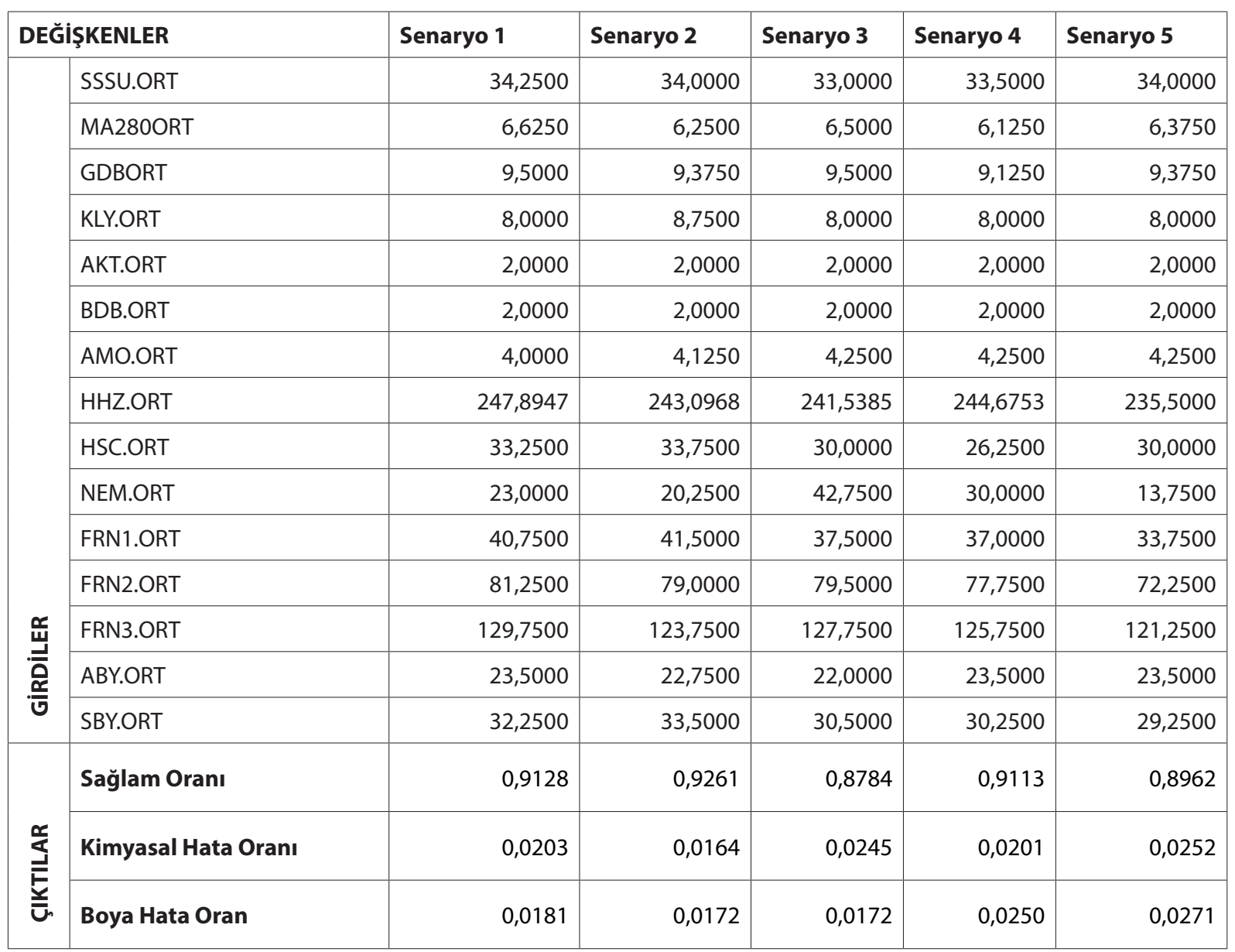


Çıktı değişkenlerinin gerçek değerleri ile ağın ürettiği sonuçların karşılaştırıldığı Şekil 5'de görüldüğü üzere gerçek değerler bazı dönemlerde ortalamanın çok dışında belirgin farklılıklar göstermektedir. Bunun sebebi beklenmeyen bir durum, herhangi bir arıza ya da gecikme gibi olağandışı durumlar olabilmektedir. Yapay sinir ağının, böylesi durumlarda genel trendi göz önüne alarak bir davranış sergilemesi beklenmektedir. Nitekim Şekil 5'deki SO ve KO grafiklerinde 1-10 dönem aralığında, BHO grafiğinde ise 100-109 dönem aralığında gerçek değerlere ait değişkenlerin, olağan durumun dışında sapma gerçekleştirdiği görülmektedir. Yapay sinir ağının ürettiği tahmin ağı ise bu dönemlerde olağan durumun dışında gerçek değerlerinki gibi yukarı yönlü bir pik yapmasına rağmen olağan durumda kalma yönünde bir davranış sergilemektedir. Yapay sinir ağından beklenen mevcut durumu göz önüne alıp öğrenme faaliyetini gerçekleştirerek daha iyi durumu ortaya koyabilmesidir. Buradan hareketle ağın gerçek duruma yakın ama kendine has davranış sergilemesi, ağın ezber yapmadığının da bir göstergesi olarak yorumlanabilir.

Hata oranlarının azaltılması ve sağlam oranının artırılması yönünde girdi değişkenleri üzerinde yapılabilecek değişikliklerin olası sonuçları mevcut model ile test edilebilmektedir. Bu yolla imalat sürecinin iyileştirilmesine çalışıımıştır. Çalışmanın sonraki aşamasında, en az hata ve en fazla sağlam oranını elde etmeye yönelik optimum girdi değişkenleri kompozisyonunu, öğrenme kabiliyetini kullanarak kendi kendine tespit edebileceği ve bu yolla süreç optimizasyonunu sağlayabileceği düşünülen bir yapay sinir ağı modeli üzerinde çalışılması planlanmaktadır.

\section{KAYNAKLAR}

Abbasi, B. (2009) "A neural network applied to estimate process capability of non-normal processes" Expert Systems with Applications, 36: 3093-3100.

Alguindigue, I. E., Loskiewicz-Buczak, A. ve Uhrig, R. E. (1993) "Monitoring and diagnosis of rolling element bearings using artificial neural Networks" IEEE transactions on industrial electronics, 40(2): 209-217.

Andersen, K., Cook, G. E., Karsai, G. ve Ramaswamy, K. (1990) “Artificial neural networks applied to arc welding process modeling and control" IEEE Transactions on industry applications, 26(5): 824-830.

Azadeh, A., Saberi, M. ve Anvari, M. (2010) “An integrated artificial neural network algorithm for performance assessment and optimization of decision making units" Expert Systems with Applications, 37(8): 5688-5697.

Azimi, P. ve Soofi, P. (2017) “An ANN-based optimization model for facility layout problem using simulation technique" Scientia Iranica E, 24(1): 364-377.

Basheer, I.A. ve Hajmeer, M. (2000) "Artificial neural networks: fundamentals, computing, design, and application" Journal of Microbiological Methods, 43: 3-31.

Burduk, A., Chlebus, T. ve Waszkowski, R. (2017, Eylül) "Assessment of the Feasibility of a Production Plan with the Use of an Artificial Neural Network Model" In: International Conference on Intelligent Systems in Production Engineering and Maintenance, s. 179-188. Springer, Cham.
Carbonneau, R., Laframboise, K. ve Vahidov, R. (2008) "Application of machine learning techniques for supply chain demand forecasting" European Journal of Operational Research, 184(3): 1140-1154.

Chen, F. L. ve Liu, S. F. (2000) “A neural-network approach to recognize defect spatial pattern in semiconductor fabrication" IEEE transactions on semiconductor manufacturing, 13(3): 366-373.

Chou, P. Y., Tsai, J. T. ve Chou, J. H. (2016) "Modeling and optimizing tensile strength and yield point on a steel bar using an artificial neural network with taguchi particle swarm optimizer" IEEE Access, 4: 585-593.

Confalonieri, M., Barni, A., Valente, A., Cinus, M. ve Pedrazzoli, P. (2015, Haziran) "An Al based decision support system for preventive maintenance and production optimization in energy intensive manufacturing plants" In:Engineering, Technology and Innovation/International Technology Management Conference (ICE/ITMC), IEEE International Conference on, s. 1-8, IEEE.

Ding, L. ve Matthews, J. (2009) “A contemporary study into the application of neural network techniques employed to automate CAD/CAM integration for die manufacture" Computers and Industrial Engineering, 57(4): 1457-1471.

Dorofki, M., Elshafie, A. H., Jaafar, O., Karim, O. A. ve Mastura, S. (2012) "Comparison of artificial neural network transfer functions abilities to simulate extreme runoff data" International Proceedings of Chemical, Biological and Environmental Engineering, 33: 39-44. 
Efendigil, T., Önüt, S. ve Kahraman, C. (2009) "A decision support system for demand forecasting with artificial neural networks and neuro-fuzzy models: A comparative analysis" Expert Systems with Applications, 36: 6697-6707.

Fast, M. ve Palme, T. (2010) "Application of artificial neural networks to the condition monitoring and diagnosis of a combined heat and power plant" Energy, 35(2), 1114-1120.

González-Romera, E., Jaramillo-Morán, M. A. ve Carmona-Fernández, D. (2008) “Monthly electric energy demand forecasting with neural networks and Fourier series" Energy Conversion and Management, 49(11), 3135-3142.

Gumus, A. T., Guneri, A. F., ve Ulengin, F. (2010) "A new methodology for multi-echelon inventory management in stochastic and neuro-fuzzy environments" International Journal of Production Economics, 128(1): 248-260.

Haas, D.J., Milano, J. ve Flitter, L. (1995) "Prediction of helicopter component loads using neural Networks" Journal of the American Helicopter Society, 40(1): 72-82.

Hakimpoor, H., Arshad, K.A.B., Tat, H.H., Khani, N. ve Rahmandoust, M. (2011) "Artificial Neural Networks' Applications in Management" World Applied Sciences Journal, 14 (7): 1008-1019.

Hurrion R.D. (1997) "An example of simulation optimization using a neural network metamodel: Finding the optimum number of kanbans in manufacturing system" Journal of Operations Research Society, 48(11), 1105-1112.

Janikova, D. ve Bezak, P. (2016, Eylül) "Prediction of production line performance using neural Networks" In: Artificial Intelligence and Pattern Recognition (AIPR), International Conference on, s. 1-5, IEEE.

Lacher, R. C., Coats, P. K., Sharma, S. C. ve Fant, L. F. (1995) "A neural network for classifying the financial health of a firm" European Journal of Operational Research, 85(1): 53-65.

Lechevalier, D., Hudak, S., Ak, R., Lee, Y.T. ve Foufou, S. (2015, Ekim) "A neural network meta-model and its application for manufacturing" In: Big Data (Big Data), IEEE International Conference on, s. 1428-1435, IEEE.

Levin, A.U. ve Narendra, K.S. (1993) "Control of nonlinear dynamical systems using neural networks:
Controllability and Stabilization" IEEE Transactions on Neural Networks, 4(2), 192-206.

Lin, Y. H., Shie, J. R. ve Tsai, C. H. (2009) “Using an artificial neural network prediction model to optimize workin-process inventory level for wafer fabrication" Expert Systems with Applications, 36(2): 3421-3427.

Mitoma, T., Wang, H. ve Chen, P. (2008) "Fault diagnosis and condition surveillance for plant rotating machinery using partially-linearized neural network" Computers \& Industrial Engineering, 55(4), 783-794.

Rosenblatt, F. (1958) "The perceptron: A probabilistic model for information storage and organization in the brain" Psychological review, 65(6): 386.

Sciuto, G., Bonaccorso, B., Cancelliere, A. ve Rossi, G. (2009) "Quality control of daily rainfall data with neural Networks" Journal of Hydrology, 364(1): 13-22.

Thomassey, S. ve Happiette, M. (2007) "A neural clustering and classification system for sales forecasting of new apparel items" Applied Soft Computing, 7(4): 1177-1187.

Upadhyaya, B. R. ve Eryurek, E. (1992) "Application of neural networks for sensor validation and plant monitoring" Nuclear Technology, 97(2): 170-176.

Yoo, J. S., Hong, S. R. ve Kim, C. O. (2009) “Service level management of nonstationary supply chain using direct neural network controller" Expert Systems with applications, 36(2): 3574-3586.

Yu, J., Xi L. ve Zhou, X. (2009) "Identifying source(s) of out-of-control signals in multivariate manufacturing processes using selective neural network ensemble" Engineering Applications of Artificial Intelligence, 22(1): 141-152.

Wang, Q. (2007) "Artificial neural networks as cost engineering methods in a collaborative manufacturing environment"International Journal of Production Economics, 109(1), 53-64.

Wang, T., Gao, H. ve Qiu, J. (2016) “A combined adaptive neural network and nonlinear model predictive control for multirate networked industrial process control" In: IEEE Transactions on Neural Networks and Learning Systems, 27(2): 416-425.

Zhang, G., Patuwo, B.E ve Hu, M.Y. (1998) “Forecasting with artificial neural networks: The state of the art" International Journal of Forecasting, 14: 35-62. 